Canadian Journal of Fisheries and Aquatic Sciences

Canadian

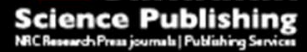

Journal canadien des sciences halieutiques et aquatiques

\title{
Growth rate and abundance of common fishes is negatively related to dissolved organic carbon concentration in lakes
}

\begin{tabular}{|r|l|}
\hline Journal: & Canadian Journal of Fisheries and Aquatic Sciences \\
\hline Manuscript ID & cjfas-2015-0340.R2 \\
\hline Manuscript Type: & Article \\
\hline Date Submitted by the Author: & $17-$ Dec-2015 \\
\hline Complete List of Authors: & $\begin{array}{l}\text { Benoît, Pierre-Olivier; McGill University, Natural Resource Sciences } \\
\text { Beisner, Beatrix; Université du Québec à Montréal, } \\
\text { Solomon, Chris; McGill University, Dept. of Natural Resource Sciences }\end{array}$ \\
\hline Keyword: & $\begin{array}{l}\text { LAKES < Environment/Habitat, DISSOLVED ORGANIC CARBON < General, } \\
\text { FRESHWATER FISHES < General, GROWTH < General, ABUNDANCE < } \\
\text { General }\end{array}$ \\
\hline &
\end{tabular}

SCHOLARONE ${ }^{m}$

Manuscripts 
1 Growth rate and abundance of common fishes is negatively related to dissolved organic

2 carbon concentration in lakes

4 Pierre-Olivier Benoît ${ }^{1,2}$, Beatrix E. Beisner ${ }^{2,3}$, and Christopher T. Solomon ${ }^{1,2,4}$

$6{ }^{1}$ Department of Natural Resource Sciences, McGill University, Montréal, Québec.

$7 \quad{ }^{2}$ Groupe de recherche interuniversitaire en limnologie et en environnement aquatique (GRIL)

$8{ }^{3}$ Department of Biological Sciences, University of Québec at Montréal, Québec.

$9 \quad{ }^{4}$ Corresponding author. Email: chris.solomon@mcgill.ca 


\section{Abstract}

11 Dissolved organic carbon (DOC) can limit food web productivity in lakes, potentially imposing

12 resource limitation on fishes. We asked whether the abundance or early growth rate of three fish

13 species was negatively related to DOC in 59 lakes in southern Québec, Canada, where DOC

14 concentrations ranged from 4 to $16 \mathrm{mg} \mathrm{L}^{-1}$ for lakes containing walleye (Sander vitreum) and

15 yellow perch (Perca flavescens) and from 2.6 to $9 \mathrm{mg} \mathrm{L}^{-1}$ for lakes containing lake trout

16 (Salvelinus namaycush). Estimates of abundance and growth rate were more precise for walleye

17 and lake trout than for yellow perch due to differences in sample size. Abundance was negatively

18 related to DOC for walleye, and perhaps also for lake trout and yellow perch. Early growth rate

19 was negatively related to DOC for walleye and lake trout, but not yellow perch. These results

20 support a growing body of literature suggesting that the productivity of fish populations may be

21 negatively related to DOC concentrations in lakes.

22 Keywords: dissolved organic carbon, allochthonous organic matter, fish, food web, productivity

\section{Résumé}

25 Le carbone organique dissous (COD) peut limiter la productivité à l'intérieur des réseaux

26 trophiques dans les lacs, imposant une limitation potentielle des ressources disponibles pour les

27 poissons. Nous avons testé si l'abondance ou le taux de croissance juvénile de trois espèces de

28 poissons étaient négativement liés à la concentration en COD dans 59 lacs du sud de la province

29 du Québec, Canada, où la concentration en COD variait entre 4 et $16 \mathrm{mg} \mathrm{L}^{-1}$ pour les lacs

30 incluant le doré jaune (Sander vitreum) et la perchaude (Perca flavescens) et entre 2,6 et $9 \mathrm{mg} \mathrm{L}^{-}$

$31{ }^{1}$ pour ceux incluant le touladi (Salvelinus namaycush). Les estimations d'abondance et les taux

32 de croissance étaient plus précis pour le doré jaune et pour le touladi par rapport à la perchaude, 
33 due à une différence au niveau de la taille d'échantillon. L'abondance était négativement reliée

34 au COD pour le doré jaune et possiblement pour le touladi et la perchaude. Le taux de croissance

35 juvénile était négativement relié au COD pour le doré jaune et le touladi mais pas pour la

36 perchaude. Ces résultats supportent un nombre croissant d'études suggérant que la productivité

37 des populations de poisson pourrait être liée négativement à la concentration de COD dans les

38 lacs.

39 Mots clés : carbone organique dissous, matière organique allochtone, poisson, chaîne

40 alimentaire, productivité

41 


\section{Introduction}

43 The factors that influence the potential productivity of inland fisheries are of substantial basic

44 and applied interest. Successful and widely-used fisheries productivity models for lakes have

45 identified factors such as nutrient availability, mean depth, availability of oxygenated habitat,

46 and others as predictors of the productivity of one or many species (Christie and Regier 1988;

47 Leach et al. 1987; Lester et al. 2004; Ryder 1965). These models have been successful in part

48 because they have built from first-principles understanding of the connections between fish

49 ecology and limnological conditions. While limnologists have long focused on nutrients as the

50 primary regulator of lake productivity, dissolved organic matter (usually measured as dissolved

51 organic carbon, DOC) is increasingly recognized as a major control on productivity in many

52 settings (Jones 1992; Prairie 2008; Solomon et al. 2015; Williamson et al. 1999)

54 In keeping with this newfound appreciation for the effects of DOC on lake productivity, recent

55 work has demonstrated negative relationships between DOC concentrations and the abundance

56 of several fishes in Scandinavian lakes (Finstad et al. 2014; Karlsson et al. 2009). Whereas

57 nutrients have often been a useful predictor of fish production because more nutrients means

58 greater productivity of the food webs that support fishes, DOC seem to be a useful predictor for

59 the opposite reason - high DOC concentrations are associated with lower food web productivity

60 (Jones et al. 2012; Kelly et al. 2014; Solomon et al. 2015). In particular, the availability of

61 zoobenthic prey seems to be the key mechanistic link between DOC concentration and fish

62 biomass (Karlsson et al. 2009). Lakes with higher DOC concentrations have lower zoobenthos

63 biomass (Craig et al. 2015; Karlsson et al. 2009). This may be because the negative effects of

64 DOC on light penetration and thereby on benthic primary production reduce the resource base 
65 available to zoobenthos (Ask et al. 2009; Godwin et al. 2014; Karlsson et al. 2009), or because

66 DOC's effect on stratification depth and thereby on dissolved oxygen concentrations imposes

67 physiological constraints on zoobenthos productivity (Craig et al. 2015). Regardless, because

68 zoobenthos are, directly or indirectly, the primary prey for most fishes in most lakes (Vander

69 Zanden and Vadeboncoeur 2002), the negative effect of DOC on zoobenthos seems to impose an

70 important resource limitation on fish populations.

72 In this study our objective was to test whether the abundance and growth rate of three common

73 North American fish species, all of which rely on benthic food chains during at least a portion of

74 their ontogeny, were negatively related to lake DOC concentration. We reasoned that if DOC

75 imposes resource limitations on fish populations by reducing zoobenthos productivity, this might

76 affect growth rates in addition to (or instead of) the abundance effects that previous studies have

77 identified. We asked whether DOC was an important predictor of abundance and growth in

78 regression models that also considered other predictors such as total phosphorus (an indicator of

79 lake productivity) and latitude (an indicator of water temperature and distributional patterns).

80 Our results extend understanding of the linkages between DOC concentrations and fish

81 productivity, and provide insights into the potential implications for fisheries management of

82 spatial variability and ongoing temporal change in lake DOC concentrations (Hanson et al. 2007;

83 Monteith et al. 2007).

\section{Methods}

86 Data sources and lake selection 
88 We used our own sampling and existing unpublished data to assemble abundance and growth

89 rate estimates across wide DOC gradients for walleye (Sander vitreum), lake trout (Salvelinus

90 namaycush), and yellow perch (Perca flavescens). Data for walleye and lake trout came from

91 Québec's Ministère des Forêts, de la Faune et des Parcs (MFFP; 74 walleye lakes and 154 lake

92 trout lakes in the initial data set; see details below). From their database we identified potential

93 focal lakes as those in the southern portion of the province for which there was adequate length-

94 age data to permit good growth rate estimates. We then used an existing lake chemistry database

95 to select lakes from this list spanning the widest possible DOC gradient. We also considered

96 travel logistics in our final selection of lakes, because our goal was to collect our own water

97 chemistry samples from each lake to minimize potential methodological variation in estimates of

98 chemical predictors in our regression models. For yellow perch, data were from our own

99 sampling efforts during May to August 2013. We identified probable yellow perch lakes in the

100 southern portion of the province based on the MFFP's database (which indicated presence of this

101 species), and again used the chemical database to pick lakes across a wide DOC gradient, and

102 travel logistics. Some lakes sampled for perch were also included in our walleye or lake trout

103 data sets.

104

105 Lake characteristics

106 We measured mixed layer DOC and TP concentrations on a pooled water sample (top, middle,

107 and bottom of mixed layer) collected with a Van Dorn bottle near the deepest point of each lake.

108 DOC samples were filtered through $0.7 \mu \mathrm{m}$ glass microfiber filters and analyzed on an Aurora

109 1030W TOC Analyzer. TP samples were analyzed by measuring absorbance at $890 \mathrm{~nm}$ after

110 persulfate digestion (Murphy and Riley 1962; Wetzel 2001). Sampling was conducted between 
111 May and August 2013 for most lakes, but for 18 lakes we used DOC and TP measurements that

112 had been made previously using similar methods (Table S1).

114 Fish sampling, abundance, and growth rate

115 Abundance and length-age data for walleye and lake trout came from standardized surveys

116 conducted by Québec's MFFP between 1988 and 2012. Experimental gill nets composed of eight

$117 \quad 7.6 \mathrm{~m}$ by $1.8 \mathrm{~m}$ panels ranging from 25 to $152 \mathrm{~mm}$ stretch mesh were set perpendicular to shore

118 and fished overnight (including at least the period from 18:00 to 09:00) for 18-24 hours. For

119 walleye, sampling was conducted in autumn and nets were set at depths between 0 and $15 \mathrm{~m}$. For

120 lake trout, sampling was conducted in late summer and nets were set at depths corresponding to

121 preferred habitat in each lake $\left(<12^{\circ} \mathrm{C}\right.$ and $>5 \mathrm{mg} \mathrm{L}^{-1}$ dissolved oxygen $)$, but not deeper than 40

$122 \mathrm{~m}$. Total effort for each lake-year sampled varied depending on lake surface area, from 4 net-

123 nights in lakes $<200$ ha to 48 net-nights in lakes $>10,000$ ha for walleye, and from 5 net-nights in

124 lakes $<150$ ha to 50 net-nights in lakes $>5,000$ ha for lake trout. In some cases additional nets

125 were set to target particular species or size classes; these sets were excluded from calculations of

126 abundance but included in length-age data sets. Complete details of these methods are provided

127 by Service de la Faune Aquatique (2011).

128

129 We used similar methods to collect yellow perch between May and August 2013. Experimental

130 gill nets composed of four $7.6 \mathrm{~m}$ by $2.4 \mathrm{~m}$ panels ranging from 38 to $89 \mathrm{~mm}$ stretch mesh were

131 set perpendicular to shore and fished overnight (including at least the period from 19:00 to

132 05:00) for 12 to 16 hours. Due to restrictions on our collector's permit intended to minimize

133 mortality of coldwater species, the bottom edge of these nets never extended below the 
134 thermocline. Total effort for each lake was 4 net-nights. We also used a beach seine ( $7.6 \mathrm{~m}$ long, $13513 \mathrm{~mm}$ mesh), minnow traps (25 mm mouth aperture), and a fyke net (6 mm mesh, $18 \mathrm{~m}$ wings)

136 to capture additional yellow perch for length-age analysis; captures from these gears were

137 excluded from calculations of abundance. All use of fish in this study was in accordance with our 138 institutional animal care and use protocol.

140 Total length of captured fish was measured to the nearest millimeter, and mass was measured to

141 the nearest gram using an electronic or spring balance. Sagittal otoliths were extracted from a

142 subset of individuals, sectioned in the transverse plane, and examined under a microscope to

143 determine age. A single reader examined each otolith on two occasions separated by $\sim 3$ months,

144 examined the second otolith of any fish for which the two readings did not agree, and discarded

145 from the data set any fish for which the age remained uncertain at that point. The resulting age

146 estimates agreed closely with those from two independent readers who examined a subset of the

147 otoliths. Most of the data in each lake were from fish aged 0 to 11 for walleye, 0 to 14 for lake

148 trout, and 0 to 8 for yellow perch; maximum ages in the data set were 34,41 , and 16 years

149 respectively. We used catch per unit effort (CPUE; individuals * net-night ${ }^{-1}$ ) and biomass per

150 unit effort (BPUE; kg wet weight * net-night ${ }^{-1}$ ), calculated across all of the standardized gillnet

151 sampling in each lake, as indices of abundance, and used the standard deviation of each index

152 across net-nights to describe the precision of these estimates. To estimate growth rates, we fit the

153 Gallucci and Quinn (1979) parameterization of the von Bertalanffy growth model to the length-

154 age data for each species in each lake:

$155[1]$ length $=\frac{\omega}{k}\left(1-e^{-k * a g e}\right)$ 
156 In this parameterization the $\omega$ parameter describes the early growth rate and has units of length

157 per time. We fit this model to the data by maximum likelihood, with a Gamma likelihood. We

158 described the precision of the $\omega$ estimates by estimating the standard error of $\omega$ from the

159 information matrix (Bolker 2008). We did not distinguish between male and female fish in this

160 analysis, and did not record sex for the yellow perch that we collected (sex ratios for walleye and

161 lake trout are given in Table S1). We reasoned that sexual dimorphism in size at age should have

162 little effect on estimates of early growth rate, because the dimorphism is most pronounced for

163 older fish whereas younger fish provide most of the information that constrains the early growth

164 rate parameter. Indeed, initial analyses demonstrated that there were significant differences

165 between male and female growth rates for only 4 of the 18 walleye lakes and 1 of the 16 lake

166 trout lakes, and that the sex-specific estimates were on average within $14 \%$ and $18 \%$ of the

167 overall estimate for walleye and lake trout respectively. All statistical analyses were conducted

168 using the R software (2014).

170 Regression analyses

171 We fit multiple regression models to the abundance and growth rate data to isolate any effect of

172 DOC while controlling for other potentially important factors. Specifically, we considered

173 latitude, surface area, TP, and DOC as predictors of CPUE and BPUE; and all of these predictors

174 plus CPUE as predictors of growth rates. We used CPUE instead of BPUE as an indicator of

175 abundance in the growth rate models because the average precision $(\mathrm{CV})$ of replicate measures

176 within a lake was slightly better for CPUE than for BPUE for all three species. We also ran but

177 do not present models using BPUE as the abundance predictor; because CPUE and BPUE were

178 strongly correlated, results were similar for these models. We fit models including all possible 
179 combinations of predictors, ranked the models by AICc, and retained models with $\triangle \mathrm{AICc}<4$.

180 The growth rate estimate for each lake was weighted by the inverse of its variance. All predictors

181 and response variables were log-transformed prior to analysis. To convey visually the

182 relationship between the response variables and DOC in particular, we plotted the response (or

183 the residuals from a regression of the response on an important predictor such as latitude) versus

184 DOC. We also used hierarchical partitioning to estimate the independent effect of each predictor 185 on the response variables (Chevan and Sutherland 1991; Mac Nally 2000).

187 Results

188 The lakes in our data set were located between 45.0 and $48.7^{\circ} \mathrm{N}$ latitude, and ranged in surface 189 area from 20 to 91,000 ha, in $\mathrm{TP}$ concentration from 2 to $160 \mu \mathrm{g} \mathrm{L} \mathrm{L}^{-1}$, and in DOC concentration

190 from 2.6 to $16.0 \mathrm{mg} \mathrm{L}^{-1}$ (Table S1). The range of DOC concentrations was wider for walleye and 191 yellow perch lakes ( 4.3 to $16.0 \mathrm{mg} \mathrm{L}^{-1}$ and 4.1 to $15.8 \mathrm{mg} \mathrm{L}^{-1}$, respectively) than for lake trout

192 lakes (2.6 to $8.8 \mathrm{mg} \mathrm{L}^{-1}$ ). Surface area and DOC concentration were significantly positively 193 correlated with latitude ( $\log -\log , \mathrm{r}=0.32$ and $\mathrm{r}=0.61$, respectively, $\mathrm{p}<0.03$ ), in part because lakes

194 in the relatively northern Abitibi region tended to be large and have moderate to high DOC 195 concentrations. DOC and TP concentrations were significantly positively correlated $(\log -\log$, $196 \mathrm{r}=0.63, \mathrm{p}<0.0001)$. None of the other correlations among latitude, surface area, TP, and DOC 197 were significantly different from zero $(\mathrm{p}>0.21)$.

199 Because our walleye and lake trout data often came from multiple samples over multiple years, 200 whereas yellow perch were sampled with a single sampling effort in each lake, the precision of 201 our abundance and early growth rate estimates was generally higher for the first two species than 
202 for perch (Table S1). The standard deviation of CPUE ranged across lakes from 6 to $60 \%$ of the 203 mean for walleye (mean=26\%), from 2 to $127 \%$ of the mean for lake trout (mean=37\%), and

204 from 34 to $200 \%$ of the mean for yellow perch (mean=90\%). These patterns also held for BPUE.

205 Similarly, the number of fish for which length-age data were available was higher for walleye 206 (range 20 to 1,720 individuals, mean=468) and lake trout (range 34 to 818 , mean=255) than for

207 yellow perch (range 30 to 57 , mean=44). Consequently, estimated early growth rates $(\omega)$ were

208 generally well-constrained for walleye and lake trout, but less so for yellow perch. The standard

209 error of $\omega$ ranged across lakes from 1 to $8 \%$ of the mean for both walleye and lake trout (mean 3-

$2104 \%$ ), whereas for yellow perch it ranged from 2 to $22 \%$ of the mean (mean $7 \%$ ).

211

212 Abundance of walleye, and perhaps also lake trout and yellow perch, was negatively related to

213 DOC concentration (Table 1, Figure 1). We report results using both CPUE and BPUE as the

214 response variable for each species, although these two measures were fairly strongly correlated

$215(\mathrm{r}=0.85,0.93$, and 0.90 for walleye, lake trout, and yellow perch respectively; log-log). For

216 walleye, a negative DOC effect appeared in all of the top models for BPUE, and in the best

217 model for CPUE (although other models for CPUE that did not include the DOC term had

218 similar predictive power). For lake trout and yellow perch the DOC effect on BPUE and CPUE

219 was always negative when it appeared in one of the top models, and for yellow perch CPUE the

220 addition of DOC to a model with latitude explained some additional variance, but in general for

221 these two species the DOC effect was described as well or better by alternative predictors like

222 total phosphorus, surface area, or latitude. Latitude was a good predictor of abundance for all

223 three species, and its independent contribution to explaining abundance was larger than that of 
224 DOC or any other predictor. Walleye were more abundant, and lake trout and yellow perch less 225 abundant, in lakes at higher latitudes within our dataset.

227 Early growth rates were negatively related to DOC concentration for walleye and lake trout, but 228 not for yellow perch (Table 2, Figure 2). For walleye, there was a clear negative relationship 229 between early growth rate and abundance, with CPUE appearing in all of the top models and 230 explaining $23 \%$ of the variation in growth rate on its own. An additional $20 \%$ of the variation in 231 walleye early growth rate was describable as a negative relationship with latitude and/or DOC 232 concentration, which were strongly correlated in the walleye lakes $(r=0.77, \log -\log )$. The 233 predictive ability of the DOC and CPUE model was indistinguishable from that of the latitude 234 and CPUE model $(\triangle \mathrm{AICc}=0.7)$, and a model including both DOC and latitude along with CPUE 235 retained the negative DOC effect and was within the set of plausible models. Latitude made the 236 largest independent contribution to explaining walleye early growth rate (37\%), followed by

237 DOC (26\%) and CPUE (23\%). For lake trout, early growth rate was clearly negatively related to 238 DOC concentration and positively related to TP concentration. The best model included both of 239 these predictors and described $51 \%$ of the variation in lake trout early growth rates. In the 240 hierarchical partitioning analysis, DOC made the largest independent contribution to explaining 241 early growth rates for lake trout (48\%), followed by latitude (22\%) and TP (15\%). For yellow

242 perch, early growth rates were uncertain, and not clearly linked to any of the predictors that we 243 considered. 
246 Our results suggest that the productivity of several common fish species may be negatively

247 related to DOC concentrations in lakes via decreases in abundance and/or early growth rates.

248 These results are consistent with those described by Karlsson et al. (2009) for Arctic char

249 Salvelinus alpinus and Eurasian perch Perca fluviatilis in northern Sweden, and by Finstad et al.

250 (2014) for brown trout Salmo trutta in Norway, but extend those results in two important ways.

251 First, our results expand the geographic range and set of species for which negative DOC effects

252 on fish productivity have been demonstrated. Second, we show that high DOC concentrations

253 may reduce early growth rates of fishes despite concomitant decreases in abundance that might

254 be expected to yield density-dependent increase in growth.

256 An important limitation of our study, which it shares with those by Karlsson et al. (2009) and

257 Finstad et al. (2014), is that it is correlative. While correlative studies across natural gradients are

258 a useful and valid method of inference, understanding of the linkages between DOC and fish

259 productivity would be strengthened by complementary inferential approaches such as planned or

260 natural experimental manipulations of DOC concentration.

262 Two previous studies in the region in which we conducted our work have taken advantage of

263 natural experiments that altered DOC concentrations to look at effects on young-of-year (YOY)

264 yellow perch. In a study of 22 lakes before and after some experienced increases in DOC

265 concentration as the result of logging in their watersheds, Bertolo and Magnan (2007) noted that

266 abundance of young-of-year perch increased with the magnitude of the DOC increase. They

267 interpreted this to be the result of either increased zooplankton productivity or reduced

268 ultraviolet radiation damage on eggs and larvae with DOC increase. Similarly, Leclerc et al. 
269 (2011) observed greater Daphnia abundance, higher YOY perch consumption of Daphnia, and

270 faster YOY perch growth rates in three lakes where DOC had increased due to logging than in

271 three control lakes.

272

273 While these studies focused only on YOY perch, they provide some experimental evidence that

274 DOC can indeed influence fish productivity. Interestingly, both of these studies, as well as

275 another correlative study conducted in northern Ontario (Tanentzap et al. 2014), showed positive

276 relationships between DOC and the abundance or growth of YOY perch. Given that YOY perch

277 are largely zooplanktivorous, this perhaps suggests net positive effects of DOC on zooplankton

278 productivity over the DOC ranges considered in these studies. Our own recent whole-lake DOC

279 manipulation experiment showed that modest increases in DOC can increase zooplankton

280 productivity, even where comparative studies across broad DOC gradients demonstrate negative

281 relationships between DOC and zooplankton productivity (Kelly et al. 2014; Zwart et al. 2016;

282 Kelly et al. unpublished manuscript). Furthermore, the results of Finstad et al. (2014) highlight

283 the context-dependence of these patterns, showing that brown trout abundance, while generally

284 negatively related to DOC concentration, is instead positively related in lakes with extremely low 285 DOC.

286

287 As this discussion demonstrates, the processes by which DOC influences food web and fish 288 productivity are complex (Solomon et al. 2015; Stasko et al. 2012). Additional manipulative 289 experiments could improve our understanding of these phenomena. Furthermore, future survey290 based studies like ours would benefit from increased sampling effort, in terms of the number of

291 fish within a lake (to increase precision of growth and abundance estimates), the number of lakes 
292 sampled across broad environmental gradients (to improve statistical separation of potentially

293 correlated effects), and the number of environmental covariates considered (to distinguish

294 potential mechanisms underlying observed patterns). For example, the strong effects of latitude

295 on abundance and growth rate in our analysis could potentially be due to differences in

296 temperature or to other factors (Venturelli et al. 2010), and other factors like angler harvest and

297 intra-specific competition might also affect abundance and growth. Data from ongoing

298 monitoring efforts by fisheries management agencies could be extremely valuable in this regard,

299 as it was in our own study. Given the limitations of correlative studies, it is notable that DOC

300 consistently emerged as a useful predictor of abundance and growth in our analyses, with the

301 hypothesized negative effect.

302

303 A negative effect of DOC on growth and abundance is consistent with the idea that DOC limits

304 fish production by limiting zoobenthos production. All three of the species that we considered

305 rely heavily on zoobenthos, or on fish that eat zoobenthos, as their prey base during most of their

306 ontogeny. For instance, total direct and indirect reliance on zoobenthos, estimated from gut

307 content data, averaged 58\% in 20 populations of walleye, $53 \%$ in 70 populations of lake trout,

308 and $77 \%$ in 90 populations of yellow perch (Vander Zanden and Vadeboncoeur 2002). The

309 differences between species that we observed in the strength of the relationships between DOC

310 and growth and abundance may be linked to differences in their ecology, as we discuss next.

\section{Species-specific responses}

313 High DOC concentrations appear to have particularly strong effects on walleye; both abundance

314 and early growth rate were lower in darker lakes, despite the potential for density-dependent 
315 increases in growth at low abundance. This result fits well with previous work on the

316 determinants of walleye productivity, and suggests some interesting new insights. Walleye rely

317 heavily on benthic food chains and this trophic niche remains fairly constant across broad DOC

318 gradients (Stasko et al. 2015). Because walleye foraging activity is linked to ambient light levels,

319 previous work has used the area of benthic habitat with suitable light levels, along with the

320 temperature preferences of walleye, to predict walleye yield across lakes (Lester et al. 2004). Our

321 results are consistent with that yield model, because high DOC concentrations reduce light

322 penetration and thermocline depth, particularly in smaller lakes (Solomon et al. 2015). On the

323 other hand, the other important predictor in the yield model is total dissolved solids (TDS)

324 (Lester et al. (2004), which serves as an indicator of productivity and is positively related to

325 walleye yield. DOC is a small component of the total dissolved solids, and higher DOC

326 concentrations tend to be associated with greater nutrient concentrations. But evidence from lake

327 surveys and modelling analyses shows that the negative effects of DOC on within-lake primary

328 and secondary productivity, via changes in light availability, thermal structure, and oxygen

329 availability, may outweigh the positive effects of nutrient increases associated with higher DOC

330 (Ask et al. 2009; Craig et al. 2015; Godwin et al. 2014; Jones et al. 2012; Kelly et al. 2014). Our

331 finding that DOC concentration is negatively related to walleye abundance and growth, and is a

332 better predictor of these responses than nutrient (TP) concentration, suggests that examining both

333 DOC and TDS might improve predictions of walleye productivity.

335 For lake trout we observed a clear DOC effect on early growth rate, but only modest evidence for

336 a DOC effect on abundance. Lake trout may rely heavily on benthic food chains, particularly as

337 juveniles but also as adults foraging in shallow water from fall through spring or in brief forays 
338 above the thermocline during summer (Dolson et al. 2009; Vander Zanden and Vadeboncoeur

339 2002). In this context a strong link between DOC concentration and early growth makes sense,

340 as higher DOC concentrations could limit zoobenthos productivity. Lake trout abundance, on the

341 other hand, is strongly constrained by the availability of cold and well-oxygenated habitat during

342 the summer (Christie and Regier 1988). While DOC does affect these physical habitat

343 characteristics, as described in the previous paragraph, these effects are modest across the limited

344 DOC range of lake trout lakes in our data set or in general, especially for larger lakes where wind

345 mixing is important (Pérez-Fuentetaja et al. 1999; Read et al. 2012; Schindler and Gunn 2004).

347 We expected to find a negative effect of DOC on early growth of yellow perch, as we observed

348 for walleye. These two species are ecologically relatively similar, and perch have higher average

349 benthic reliance than walleye (Vander Zanden and Vadeboncoeur 2002). Instead, we observed a

350 strong effect of DOC on perch abundance measured by CPUE, but no effect on growth. There

351 are at least two possible explanations for this unexpected result. First, the lack of growth effect

352 could be linked to the relatively limited data that we had for perch, consisting of relatively few

353 individuals captured in a single year in each lake. In contrast, the estimates for walleye and lake

354 trout were derived from much larger samples and often included data from multiple years.

355 Consequently, the growth rate estimates for perch were less well constrained and did not

356 integrate over year-to-year or cohort-to-cohort variability in growth within a lake (Table S1). The

357 observation that none of the predictors that we considered explained much variability in the

358 perch growth rate estimates is also consistent with this interpretation. Second, it could be that the

359 smaller size of perch relative to walleye, and their greater tendency towards planktivory at small

360 sizes, provides some buffer against the loss of energy-dense benthic prey in high-DOC lakes. 
361 Work on Eurasian perch (Perca fluviatilis), for instance, shows that while the diet of fish 100-

$362200 \mathrm{~mm}$ long is heavily dominated by benthic invertebrates, greater amounts of zooplankton

363 appear in the diet in years when high density forces fish to forage in the pelagic zone (Persson et

364 al. 2000). Some evidence, however, indicates that zooplankton production is also negatively

365 related to DOC concentration (Kelly et al. 2014), suggesting that a shift to planktivory might not

366 be able to offset the loss of benthic prey in higher-DOC systems. Further work is needed to

367 assess how the strong environmental gradients imposed by DOC affect feeding strategies and

368 energetic budgets of perch and other fishes (Estlander et al. 2015).

370 Fisheries management and DOC

371 Our results support a growing body of literature suggesting that the productivity of many fish

372 populations is negatively related to DOC concentrations. Many of the species for which this

373 pattern has been demonstrated support important recreational, subsistence, and commercial

374 fisheries, yet the negative effects of DOC on fish productivity are not typically incorporated into

375 the fisheries models used for management. Incorporating DOC effects into these models might

376 improve our ability to manage these fisheries sustainability, especially given the great

377 heterogeneity of lake DOC concentrations across lake landscapes and ongoing changes in DOC

378 concentrations in some regions (Hanson et al. 2007; Monteith et al. 2007; Solomon et al. 2015).

379 At a more fundamental level, additional work using multiple modes of inference is needed to

380 further elucidate the mechanisms by which DOC effects on fish productivity occur.

381

382 Acknowledgements 
383 Walleye and lake trout data were provided by Québec's Ministère des Forêts, de la Faune et des

384 Parcs; we particularly appreciate the help of J. Deschênes, M. Arvisais, I. Thibault, V. Leclerc,

385 D. Hatin, and the numerous field biologists who contributed to generating these data. D. Benoit

386 provided invaluable help in the field and the lab. Y. Prairie and P. del Giorgio contributed lake

387 physical-chemical data, as did L. Roy and the Direction du suivi de l'état de l'environnement

388 (Ministère du Développement Durable de 1'Environnement et de la Lutte aux Changements

389 Climatiques). The reviewers suggested the hierarchical partitioning analysis and many useful

390 improvements. This project was supported by grants from the Natural Sciences and Engineering

391 Research Council of Canada (NSERC) and the Fonds de Recherche du Québec - Nature et

392 Technologies (FRQNT), including the Groupe de Recherche Interuniversitaire en Limnologie et

393 en environnement aquatique (GRIL).

394

395 Supplementary information - See supplementary data in Table S1.

\section{$397 \quad$ Literature cited}

398 Ask, J., Karlsson, J., Persson, L., Ask, P., Bystrom, P., and Jansson, M. 2009. Terrestrial organic

399 matter and light penetration: Effects on bacterial and primary production in lakes. Limnol.

$400 \quad$ Oceanogr. 54(6): 2034-2040.

401 Bertolo, A., and Magnan, P. 2007. Logging-induced variations in dissolved organic carbon affect

402 yellow perch (Perca flavescens) recruitment in Canadian Shield lakes. Can. J. Fish. Aquat.

403 Sci. 64(2): 181-186.

404 Bolker, B.M. 2008. Ecological Models and Data in R. Princeton University Press, Princeton, $405 \quad$ New Jersey. 
Chevan, A., and Sutherland, M. 1991. Hierarchical Partitioning. Am Stat 45(2): 90-96.

407 Christie, G.C., and Regier, H.A. 1988. Measures of optimal thermal habitat and their relationship

408 to yields for 4 commercial fish species. Can. J. Fish. Aquat. Sci. 45(2): 301-314.

409 Craig, N., Jones, S.E., Weidel, B.C., and Solomon, C.T. 2015. Habitat, not resource availability, 410 limits consumer production in lake ecosystems. Limnol. Oceanogr. 60: 2079-2089.

411 Dolson, R., McCann, K., Rooney, N., and Ridgway, M. 2009. Lake morphometry predicts the 412 degree of habitat coupling by a mobile predator. Oikos 118(8): 1230-1238.

413 Estlander, S., Nurminen, L., Mrkvička, T., Olin, M., Rask, M., and Lehtonen, H. 2015. Sex414 dependent responses of perch to changes in water clarity and temperature. Ecology of $415 \quad$ Freshwater Fish 24(4): 544-552.

416 Finstad, A.G., Helland, I.P., Ugedal, O., Hesthagen, T., and Hessen, D.O. 2014. Unimodal 417 response of fish yield to dissolved organic carbon. Ecology Letters 17(1): 36-43.

418 Gallucci, V.F., and Quinn, T.J. 1979. Reparameterizing, fitting, and testing a simple growth 419 model. Transactions of the American Fisheries Society 108(1): 14-25.

420 Godwin, S.C., Jones, S.E., Weidel, B.C., and Solomon, C.T. 2014. Dissolved organic carbon 421 concentration controls benthic primary production: Results from in situ chambers in north422 temperate lakes. Limnol. Oceanogr. 59(6): 2112-2120.

423 Hanson, P.C., Carpenter, S.R., Cardille, J.A., Coe, M.T., and Winslow, L.A. 2007. Small lakes 424 dominate a random sample of regional lake characteristics. Freshw. Biol. 52(5): 814-822. 425 Jones, R.I. 1992. The influence of humic substances on lacustrine planktonic food-chains.

426 Hydrobiologia 229: 73-91.

427 Jones, S.E., Solomon, C.T., and Weidel, B.C. 2012. Subsidy or subtraction: How do terrestrial 428 inputs influence consumer production in lakes? Freshwater Reviews 5: 37-49. 
429 Karlsson, J., Bystrom, P., Ask, J., Ask, P., Persson, L., and Jansson, M. 2009. Light limitation of 430 nutrient-poor lake ecosystems. Nature 460(7254): 506-509.

431 Kelly, P.T., Solomon, C.T., Weidel, B.C., and Jones, S.E. 2014. Terrestrial carbon is a resource, 432 but not a subsidy, for lake zooplankton. Ecology 95(5): 1236-1242.

433 Leach, J.H., Dickie, L.M., Shuter, B.J., Borgmann, U., Hyman, J., and Lysack, W. 1987. A

434 review of methods for prediction of potential fish production with application to the Great

435 Lakes and Lake Winnipeg. Can. J. Fish. Aquat. Sci. 44: 471-485.

436 Leclerc, V., Sirois, P., and Berube, P. 2011. Impact of forest harvesting on larval and juvenile 437 growth of yellow perch (Perca flavescens) in boreal lakes. Boreal Environment Research $438 \quad$ 16(5): 417-429.

439 Lester, N.P., Dextrase, A.J., Kushneriuk, R.S., Rawson, M.R., and Ryan, P.A. 2004. Light and 440 temperature: Key factors affecting walleye abundance and production. Transactions of the $441 \quad$ American Fisheries Society 133(3): 588-605.

442 Mac Nally, R. 2000. Regression and model-building in conservation biology, biogeography and 443 ecology: The distinction between - and reconciliation of - 'predictive' and 'explanatory' 444 models. Biodiversity \& Conservation 9(5): 655-671.

445 Monteith, D.T., Stoddard, J.L., Evans, C.D., de Wit, H.A., Forsius, M., Hogasen, T., Wilander, 446 A., Skjelkvale, B.L., Jeffries, D.S., Vuorenmaa, J., Keller, B., Kopacek, J., and Vesely, J. 447 2007. Dissolved organic carbon trends resulting from changes in atmospheric deposition $448 \quad$ chemistry. Nature 450(7169): 537-540.

449 Murphy, J., and Riley, J.P. 1962. A modified single solution method for determination of 450 phosphate in natural waters. Analytica Chimica Acta 26(1): 31-\&. 
451 Pérez-Fuentetaja, A., Dillon, P., Yan, N., and McQueen, D. 1999. Significance of dissolved 452 organic carbon in the prediction of thermocline depth in small Canadian shield lakes. Aquatic $453 \quad$ Ecology 33(2): 127-133.

454 Persson, L., Bystrom, P., and Wahlstrom, E. 2000. Cannibalism and competition in Eurasian 455 perch: population dynamics of an ontogenetic omnivore. Ecology 81(4): 1058-1071.

456 Prairie, Y.T. 2008. Carbocentric limnology: Looking back, looking forward. Can. J. Fish. Aquat. $457 \quad$ Sci. 65: $543-548$.

458 Read, J.S., Hamilton, D.P., Desai, A.R., Rose, K.C., MacIntyre, S., Lenters, J.D., Smyth, R.L., 459 Hanson, P.C., Cole, J.J., Staehr, P.A., Rusak, J.A., Pierson, D.C., Brookes, J.D., Laas, A., and 460 Wu, C.H. 2012. Lake-size dependency of wind shear and convection as controls on gas $461 \quad$ exchange. Geophys Res Lett 39.

462 Ryder, R.A. 1965. A method for estimating potential fish production of north-temperate lakes.

463 Transactions of the American Fisheries Society 94(3): 214-\&.

464 Schindler, D.E., and Gunn, J.M. 2004. Dissolved organic carbon as a controlling variable in lake 465 trout and other Boreal Shield lakes. In Boreal shield watersheds: lake trout ecosystems in a 466 changing environment. Edited by J. Gunn, R.J. Steedman and R. Ryder. CRC Press.

467 Service de la Faune Aquatique. 2011. Guide de normalisation des méthodes d'inventaire 468 ichtyologiques en eaux intérieures, Tome I, Acquisition de données. Edited by M.d.r.n.e.d.1. 469 faune, Québec. p. 137.

470 Solomon, C.T., Jones, S.E., Weidel, B.C., Buffam, I., Fork, M.L., Karlsson, J., Larsen, S., 471 Lennon, J.T., Read, J.S., Sadro, S., and Saros, J.E. 2015. Ecosystem consequences of of 472 changing inputs of terrestrial dissolved organic matter to lakes: current knowledge and future 473 challenges. Ecosystems 18(3): 376-389. 
474 Stasko, A.D., Gunn, J.M., and Johnston, T.A. 2012. Role of ambient light in structuring north-

475 temperate fish communities: potential effects of increasing dissolved organic carbon

476 concentration with a changing climate. Environmental Reviews 20(3): 173-190.

477 Stasko, A.D., Johnston, T.A., and Gunn, J.M. 2015. Effects of water clarity and other

478 environmental factors on trophic niches of two sympatric piscivores. Freshw. Biol. 60(7):

$479 \quad 1459-1474$.

480 Tanentzap, A.J., Szkokan-Emilson, E.J., Kielstra, B.W., Arts, M.T., Yan, N.D., and Gunn, J.M.

481 2014. Forests fuel fish growth in freshwater deltas. Nature Communications 5: 9.

482 Team, R.C. 2014. R: A language and environment for statistical computing. R Foundation for 483 Statistical Computing, Vienna, Austria.

484 Vander Zanden, M.J., and Vadeboncoeur, Y. 2002. Fishes as integrators of benthic and pelagic 485 food webs in lakes. Ecology 83(8): 2152-2161.

486 Venturelli, P.A., Lester, N.P., Marshall, T.R., and Shuter, B.J. 2010. Consistent patterns of 487 maturity and density-dependent growth among populations of walleye (Sander vitreus):

488 application of the growing degree-day metric. Can. J. Fish. Aquat. Sci. 67: 1057-1067.

489 Wetzel, R.G. 2001. Limnology: lake and river ecosystems. Academic Press, San Diego, CA.

490 Williamson, C.E., Morris, D.P., Pace, M.L., and Olson, A.G. 1999. Dissolved organic carbon

491 and nutrients as regulators of lake ecosystems: Resurrection of a more integrated paradigm.

492 Limnol. Oceanogr. 44(3): 795-803.

493 Zwart, J.A., Craig, N., Kelly, P.T., Solomon, C.T., Weidel, B.C., and Jones, S.E. 2016.

494 Metabolic and physiochemical responses to a whole-lake experimental increase in dissolved 495 organic carbon in a north-temperate lake. Limnol. Oceanogr. 
498 Table 1. Regression models describing among-lake variation in abundance of walleye, lake 499 trout, and yellow perch, using catch per unit effort (CPUE) or biomass per unit effort (BPUE) as 500 abundance indices. Columns give the model rank (based on $\triangle \mathrm{AICc}$ ), the $\triangle \mathrm{AICc}$, the proportion 501 of variance explained by the model adjusted for degrees of freedom (i.e. the adjusted $\mathrm{R}^{2}$ ), and the 502 parameter estimates for the intercept, latitude, surface area, total phosphorus, and dissolved 503 organic carbon effects appearing in each model. For each species we fit models including all 504 possible combinations of these main effects, and show here all of the models that were within 4 505 AICc units of the best model. All predictors and the response variable were log-transformed, and 506 coefficients are in transformed units. The independent contribution of each variable, estimated 507 from the hierarchical partitioning analysis, is given as a percentage below the predictor name in 508 each sub-table.

510 Walleye BPUE $(\mathrm{n}=21)$

\begin{tabular}{|l|l|l|l|l|l|l|l|}
\hline Model & $\Delta \mathrm{AICc}$ & $\mathrm{R}_{\text {adj }}^{2}$ & Intercept & $\begin{array}{l}\text { Lat } \\
(50 \%)\end{array}$ & $\begin{array}{l}\mathrm{SA} \\
(13 \%)\end{array}$ & $\begin{array}{l}\mathrm{TP} \\
(5 \%)\end{array}$ & $\begin{array}{l}\mathrm{DOC} \\
(32 \%)\end{array}$ \\
\hline 1 & 0.0 & 0.33 & -136 & 37 & & & -1.8 \\
\hline 2 & 0.8 & 0.38 & -138 & 38 & -0.11 & & -1.8 \\
\hline 3 & 3.5 & 0.29 & -135 & 36 & & -0.02 & -1.8 \\
\hline
\end{tabular}

512 Walleye CPUE $(\mathrm{n}=21)$

\begin{tabular}{|l|l|l|l|l|l|l|l|}
\hline Model & $\Delta$ AICc & $\mathrm{R}^{2}$ adj & Intercept & $\begin{array}{l}\text { Lat } \\
(59 \%)\end{array}$ & $\begin{array}{l}\text { SA } \\
(14 \%)\end{array}$ & $\begin{array}{l}\text { TP } \\
(4 \%)\end{array}$ & $\begin{array}{l}\text { DOC } \\
(23 \%)\end{array}$ \\
\hline 1 & 0.0 & 0.17 & -104 & 28 & & & -1.1 \\
\hline 2 & 0.2 & 0.08 & -44 & 12 & & & \\
\hline 3 & 0.3 & NA & 2.6 & & & & \\
\hline 4 & 2.1 & 0.08 & -47 & 13 & -0.084 & & \\
\hline 5 & 2.2 & 0.17 & -105 & 29 & -0.081 & & -1.1 \\
\hline 6 & 2.4 & $<0.01$ & 3.1 & & -0.068 & & \\
\hline 7 & 3.0 & $<0.01$ & 2.3 & & & & 0.13 \\
\hline 8 & 3.0 & $<0.01$ & 2.5 & & & 0.026 & \\
\hline 9 & 3.1 & 0.14 & -109 & 30 & & 0.093 & -1.3 \\
\hline 10 & 3.2 & 0.03 & -46 & 13 & & -0.045 & \\
\hline
\end{tabular}

513

514 Lake trout BPUE $(\mathrm{n}=29)$

\begin{tabular}{|l|l|l|l|l|l|l|l|}
\hline Model & $\Delta \mathrm{AICc}$ & $\mathrm{R}_{\text {adj }}^{2}$ & Intercept & $\begin{array}{l}\text { Lat } \\
(65 \%)\end{array}$ & $\begin{array}{l}\text { SA } \\
(6 \%)\end{array}$ & $\begin{array}{l}\mathrm{TP} \\
(20 \%)\end{array}$ & $\begin{array}{l}\text { DOC } \\
(10 \%)\end{array}$ \\
\hline 1 & 0.0 & 0.27 & 109 & -28 & & & \\
\hline 2 & 1.2 & 0.28 & 121 & -32 & 0.13 & & \\
\hline 3 & 2.2 & 0.25 & 98 & -25 & & 0.21 & \\
\hline 4 & 2.7 & 0.24 & 107 & -28 & & & -0.065 \\
\hline 5 & 3.9 & 0.25 & 117 & -31 & 0.14 & & -0.22 \\
\hline 6 & 4.0 & 0.25 & 113 & -30 & 0.12 & 0.13 & \\
\hline
\end{tabular}


516 Lake trout CPUE $(\mathrm{n}=29)$

\begin{tabular}{|l|l|l|l|l|l|l|l|}
\hline Model & $\Delta \mathrm{AICc}$ & $\mathrm{R}^{2}{ }_{\text {adj }}$ & Intercept & $\begin{array}{l}\text { Lat } \\
(72 \%)\end{array}$ & $\begin{array}{l}\mathrm{SA} \\
(7 \%)\end{array}$ & $\begin{array}{l}\mathrm{TP} \\
(12 \%)\end{array}$ & $\begin{array}{l}\mathrm{DOC} \\
(8 \%)\end{array}$ \\
\hline 1 & 0.0 & 0.33 & 129 & -33 & & & \\
\hline 2 & 2.6 & 0.31 & 125 & -32 & -0.042 & & \\
\hline 3 & 2.6 & 0.31 & 126 & -33 & & & -0.12 \\
\hline 4 & 2.7 & 0.31 & 127 & -33 & & 0.032 & \\
\hline
\end{tabular}

517

518 Yellow perch BPUE $(\mathrm{n}=17)$

\begin{tabular}{|l|l|l|l|l|l|l|l|}
\hline Model & $\Delta \mathrm{AICc}$ & $\mathrm{R}_{\text {adj }}^{2}$ & Intercept & $\begin{array}{l}\text { Lat } \\
(62 \%)\end{array}$ & $\begin{array}{l}\mathrm{SA} \\
(4 \%)\end{array}$ & $\begin{array}{l}\mathrm{TP} \\
(21 \%)\end{array}$ & $\begin{array}{l}\mathrm{DOC} \\
(13 \%)\end{array}$ \\
\hline 1 & 0.0 & 0.37 & 128 & -32 & & & \\
\hline 2 & 2.8 & 0.35 & 114 & -29 & & 0.25 & \\
\hline 3 & 2.9 & 0.35 & 139 & -35 & 0.11 & & \\
\hline 4 & 3.4 & 0.33 & 123 & -31 & & & -0.17 \\
\hline
\end{tabular}

520 Yellow perch CPUE $(n=17)$

\begin{tabular}{|l|l|l|l|l|l|l|l|}
\hline Model & $\Delta \mathrm{AICc}$ & $\mathrm{R}_{\text {adj }}^{2}$ & Intercept & $\begin{array}{l}\text { Lat } \\
(43 \%)\end{array}$ & $\begin{array}{l}\text { SA } \\
(2 \%)\end{array}$ & $\begin{array}{l}\mathrm{TP} \\
(16 \%)\end{array}$ & $\begin{array}{l}\text { DOC } \\
(38 \%)\end{array}$ \\
\hline 1 & 0.0 & 0.28 & 106 & -28 & & & \\
\hline 2 & 1.6 & 0.31 & 84 & -22 & & & -0.90 \\
\hline 3 & 2.0 & 0.30 & 0.98 & & & 0.57 & -1.67 \\
\hline 4 & 2.2 & 0.18 & 2.1 & & & & -1.5 \\
\hline 5 & 3.3 & 0.24 & 98 & -26 & & 0.14 & \\
\hline 6 & 3.4 & 0.23 & 110 & -29 & 0.042 & & \\
\hline 7 & 3.7 & NA & -1.1 & & & & \\
\hline
\end{tabular}


523 Table 2. Regression models describing among-lake variation in early growth rates $(\omega ;$ Eq. 1$)$ of 524 walleye, lake trout, and yellow perch. Columns give the model rank (based on $\triangle \mathrm{AICc}$ ), the $525 \Delta \mathrm{AICc}$, the proportion of variance explained by the model adjusted for degrees of freedom (i.e.

526 the adjusted $\mathrm{R}^{2}$ ), and the parameter estimates for the intercept, latitude, surface area, total

527 phosphorus, dissolved organic carbon, and catch-per-unit-effort effects appearing in each model.

528 For each species we fit models including all possible combinations of these main effects, and

529 show here all of the models that were within 4 AICc units of the best model. All predictors and

530 the response variable were log-transformed, and coefficients are in transformed units. The

531 independent contribution of each variable, estimated from the hierarchical partitioning analysis,

532 is given as a percentage below the predictor name in each sub-table.

534 Walleye $(\mathrm{n}=18)$

\begin{tabular}{|c|c|c|c|c|c|c|c|c|}
\hline Model & $\Delta \mathrm{AICc}$ & $\mathrm{R}^{2}{ }_{\text {adj }}$ & Intercept & $\begin{array}{c}\text { Lat } \\
(37 \%)\end{array}$ & $\begin{array}{c}\text { Area } \\
(4 \%)\end{array}$ & $\begin{array}{c}\mathrm{TP} \\
(9 \%)\end{array}$ & $\begin{array}{c}\text { DOC } \\
(26 \%)\end{array}$ & $\begin{array}{c}\text { CPUE } \\
(23 \%)\end{array}$ \\
\hline 1 & 0 & 0.43 & 61 & -14 & & & & -0.31 \\
\hline 2 & 0.7 & 0.41 & 7.1 & & & & -0.51 & -0.33 \\
\hline 3 & 3.2 & 0.23 & 5.9 & & & & & -0.32 \\
\hline 4 & 3.8 & 0.39 & 49 & -11 & & & -0.13 & -0.32 \\
\hline 5 & 3.9 & 0.39 & 62 & -14 & 0.011 & & & -0.29 \\
\hline 6 & 3.9 & 0.39 & 64 & -15 & & 0.020 & & -0.31 \\
\hline 7 & 3.9 & 0.39 & 7.3 & & & 0.090 & -0.68 & -0.33 \\
\hline
\end{tabular}

Lake trout $(\mathrm{n}=16)$

\begin{tabular}{|c|c|c|c|c|c|c|c|c|}
\hline Model & $\Delta$ AICc & $\mathrm{R}^{2}{ }_{\text {adj }}$ & Intercept & $\begin{array}{c}\text { Lat } \\
(22 \%)\end{array}$ & $\begin{array}{c}\text { Area } \\
(7 \%)\end{array}$ & $\begin{array}{c}\mathrm{TP} \\
(15 \%)\end{array}$ & $\begin{array}{c}\text { DOC } \\
(48 \%)\end{array}$ & $\begin{array}{c}\text { CPUE } \\
(8 \%)\end{array}$ \\
\hline 1 & 0 & 0.51 & 5.0 & & & 0.16 & -0.38 & \\
\hline 2 & 1.6 & 0.55 & -16 & 5.4 & & 0.25 & -0.61 & \\
\hline 3 & 1.9 & 0.36 & 5.4 & & & & -0.49 & \\
\hline 4 & 3.0 & 0.31 & 4.3 & & & 0.21 & & \\
\hline 5 & 3.5 & 0.49 & 5.0 & & & 0.18 & -0.42 & -0.031 \\
\hline
\end{tabular}

538 Yellow perch $(\mathrm{n}=17)$

\begin{tabular}{|c|c|c|c|c|c|c|c|c|}
\hline Model & $\Delta \mathrm{AICc}$ & $\mathrm{R}_{\text {adj }}$ & Intercept & $\begin{array}{c}\text { Lat } \\
(12 \%)\end{array}$ & $\begin{array}{c}\text { Area } \\
(28 \%)\end{array}$ & $\begin{array}{c}\mathrm{TP} \\
(24 \%)\end{array}$ & $\begin{array}{c}\text { DOC } \\
(12 \%)\end{array}$ & $\begin{array}{c}\text { CPUE } \\
(24 \%)\end{array}$ \\
\hline 1 & 0.0 & & 4.4 & & & & & \\
\hline 2 & 0.5 & 0.08 & 4.2 & & 0.040 & & & \\
\hline 3 & 1.9 & $<0.01$ & 4.4 & & & & & -0.038 \\
\hline 4 & 2.5 & $<0.01$ & 4.5 & & & -0.043 & & \\
\hline 5 & 2.9 & $<0.01$ & 4.5 & & & & -0.040 & \\
\hline 6 & 3.0 & $<0.01$ & 4.1 & 0.077 & & & & \\
\hline
\end{tabular}




\section{$541 \quad$ Figure captions}

543 Figure 1. Relationship between abundance and dissolved organic carbon concentration (DOC)

544 for three fish species in Quebec lakes. The left column shows abundance as catch per unit effort

545 (CPUE) and the right column uses biomass per unit effort (BPUE). Abundances are plotted as

546 the residuals from regressions of each abundance index on latitude, which was an important

547 predictor of abundance for all species and both indices (see Table 1).

549 Figure 2. Relationship between early growth rate and dissolved organic carbon concentration for

550 three fish species in Quebec lakes. Data are residuals from regressions of early growth rate on

551 abundance (for walleye) or on total phosphorus concentration (for lake trout), because these were

552 identified as important predictors of growth rate for these species (see Table 2). 
arPatig 29afieal of Fišngries and Aquiatic Science

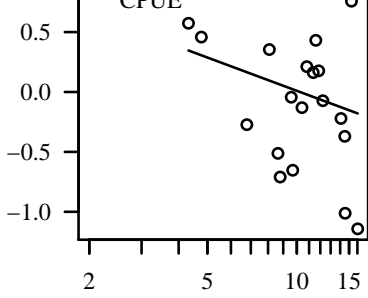

BPUE o

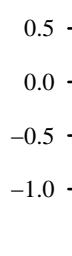

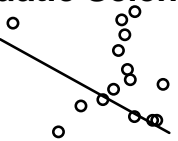

0 $1.5-\begin{aligned} & \text { lake trout o } \\ & \text { CPUE }\end{aligned}$

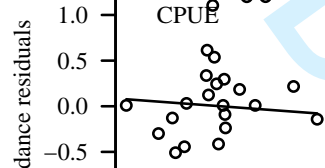

焉

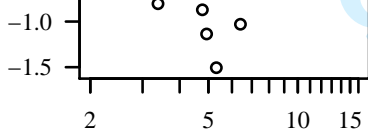

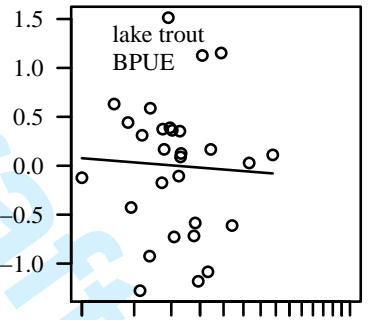

2
$10 \quad 15$
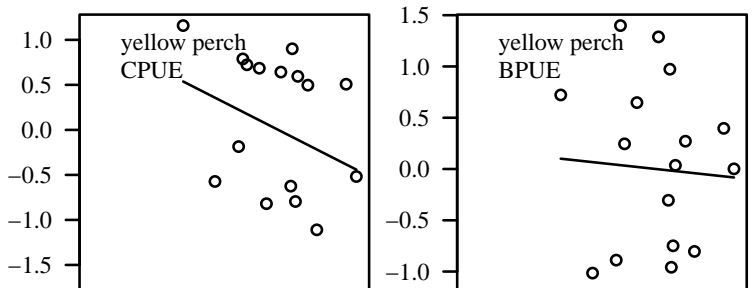

https:L/mç 
urnals of Fistherges3ondf BQ u:

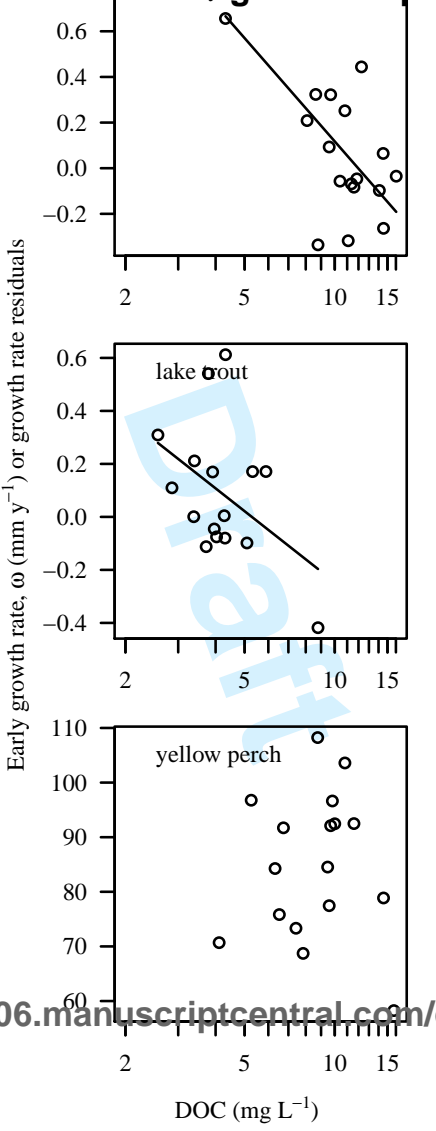

